\title{
Community participation in demanding accountability for health systems strengthening
}

\author{
YK SANDHYA, RENU KHANNA
}

\begin{abstract}
This paper describes how the COPASAH Global Symposium treated the Theme of 'Community Action in Governance and Accountability for Health System Strengthening'. We first lay out COPASAH's understanding of Social Accountability in health systems as centre-staging the transformative potential of the power of the communities rather than seeing social accountability as merely a tokenistic participation of the community. Through case studies presented by practitioners from across the globe, the Theme positioned communities and civil society at large as central to the governance and accountability of health systems (both public and private). The important role of contextual analysis in defining the strategies and interventions for demanding accountability was discussed. Participants' experiences of demanding accountability brought out clearly the importance of linkages from local action to global mobilisation. Further, the discussions reaffirmed COPASAH's principles of Social Accountability in Health that informed the COPASAH Charter and Call to Action for Social Accountability for Health.
\end{abstract}

Keywords: Social accountability, developing political capabilities, marginalised peoples' voices, citizen's report cards, empowering communities

Although movements to demand accountability from elected governments have been active and successful in countries across the world, the term social accountability (SA) in the development sector gained popularity in the 2000s. Many initiatives were undertaken in various parts of the world such as the citizen report cards in the Philippines, Albania and Uganda; community scorecards in the Gambia and Malawi (1); access to justice programmes in Indonesia and the development of a system of social accountability in

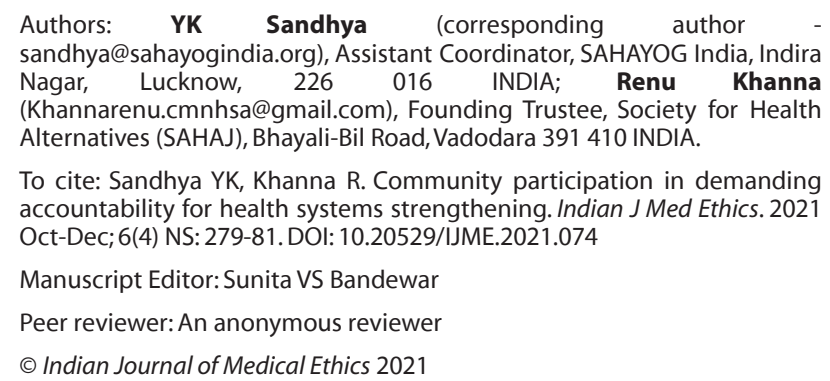

To cite: Sandhya YK, Khanna R. Community participation in demanding accountability for health systems strengthening. Indian J Med Ethics. 2021 Oct-Dec; 6(4) NS: 279-81. DOI: 10.20529/IJME.2021.074

Manuscript Editor: Sunita VS Bandewar

Peer reviewer: An anonymous reviewer

(c) Indian Journal of Medical Ethics 2021

Peru (2). Recognising these initiatives as furthering rightsbased approaches as exemplified by the World Bank's definition of social accountability as "a right grounded in a new manifestation of citizenship based on the right to hold governments accountable by expanding people's responsibility" (3).

What then is social accountability (SA)? Is it to be understood only as an approach seeking to build accountability through direct or indirect civic engagement of citizens demanding accountability from service providers and public officials? Is it limited to combining information on rights and service delivery with collective action for change through tools and mechanisms such as participatory budgeting, public expenditure tracking, citizen report cards, community score cards, social audits, citizen charters, and right to information laws? These were some of the questions that the theme on Community Participation in Accountability for Health Systems Strengthening (henceforth, CPGA) of the Global Symposium (GS) sought to explore, while unpacking COPASAH's understanding of SA.

Discussions during the CPGA questioned the dominant understanding (including that of the World Bank) of SA in the field of health, as being solely meant to enable citizens to contribute to improvement in the quality of service delivery by holding policy-makers and providers of services accountable. During the discussions, Dr Anuradha Joshi of the Institute of Development Studies, Sussex, mentioned that while various tools of social accountability were used in the pursuit of SA with the objective of informing the community about their rights, about standards of service delivery and to give information on formal redress mechanisms, it was a mistake to reduce SA to a mere "mechanism" or "widget" (4). Such a reductionist approach depoliticised the very processes through which marginalised people make claims. She emphasised that SA has to be a long term engagement that requires strategic reflection and iterative engagement and cannot be imported from some other context or, in other words, contextual conditions matter and only limited generalisations can be made from other existing studies (5).

The discussions through a series of presentations began by examining the "widgets" of SA and in the process unpacked COPASAH's conceptualisation of SA (used interchangeably with "community monitoring") which defines SA as part of a long-term ongoing political engagement of social actors 
with the state (6). Through presentations of case studies, from India, Uganda, Botswana, Sri Lanka and Guatemala, speakers recounted how citizens can collectively influence service delivery when they have access to information and the opportunity to use it to hold providers (both frontline service providers and programme managers) accountable. SA thus involves the use of information to increase transparency, improve service delivery and seek grievance redress - all of which improve accountability. The presentations highlighted that COPASAH's definition of SA is based on an accountability framework and is linked to government responsibility for the provision and/or overseeing of health services as a peoples' right. These presentations highlighted that demands for accountability at times create new spaces where none existed, but at other times engage with existing spaces to demand greater accountability, as exemplified by the Indian nongovernmental organisation, CHETNA's experience of opening up gram sabhas (statutory village bodies of all adults eligible to vote) to women, which helped to amplify women's voices leading to action at community level to make the government accountable.

COPASAH also believes that SA reflects the "people's or community perspective" on health services in situations where governments have made commitments to such services. It raises the community voice on whether governments are responding to peoples' health demands and realising people centred health-related commitments. Case studies presented by advocacy groups-from the UDN (Uganda) campaign to initiate non-confrontational dialogues leading to identification of problems in maternal and child health services and initiation of steps to improve the services; CEGSS (Guatemala) which used a range of strategies to exert pressure on authorities to open dialogue channels and negotiate with community defenders in order to solve identified issues in health service provision; and SATHI (India) efforts through the use of community-based monitoring and engaging with hospital management committees, paving the way for a decentralised health planning process for conversion of people's health demands into budget proposals-all brought this out. In all these interventions the lived experience of community efforts led to framing and identifying of the issue, generating evidence, and using the evidence to engage with the public health system and negotiating for greater control. Thus, SA was seen as an "empowering process" where the capacities of participating individuals/community were enhanced to address power imbalances adversely impacting peoples' health. The cases also clearly brought out another element of SA - that is, SA initiatives are linked to an "advocacy/action plan", aimed at improving the implementation of health policies and programmes. Thus, SA is not a stand-alone activity with information collection as an end in itself.

Discussions also highlighted how SA practitioners in the course of their work had to weigh carefully which approaches, tools and techniques worked best in different contextual realities, as context affected outcomes, and ways in which the intervention actually played out. The Indian intervention, for instance, was successful because the government was interested in the collaboration. In the Ugandan case, it was the acceptance of the monitors by the community which contributed to success. On the other hand, in the Guatemala case, success resulted from the users of the services being drivers of change. In Botswana, collaborations had to be established with health providers to enable the rights of the community to be realised. The cases presented thus resonated with Anuradha Joshi's point that SA initiatives may include macro or micro-contextual factors. On the macro-side (country level), accountability processes need to take into account broad factors such as national histories of citizen-state engagement; while on the micro side, local factors could drive the extent to which social accountability initiatives are successful, even within broadly similar national contexts (7).

Practitioners at CPGA also deliberated on how to evaluate whether an SA initiative was successful and impactful. The participants reiterated that the focus should not be on identifying tangible changes alone, but also on capturing incremental shifts as is exemplified in the case studies. In Uganda for instance, the intervention led to an $11 \%$ reduction in stock-outs with improved timely supply and availability of drugs across the 33 health facilities, as well as a reduced waiting time at health facilities from five hours to an average of two hours. Similarly, in India, CHETNA was able to empower women to make proposals or demands in local council meetings, for their entitlements, to improve the quality of health services, leading to resolutions being passed, resulting in the improvement of the quality of services.

These deliberations revealed that SA is a complex social intervention, which not only brings about complementary outcomes but sets in motion social processes which act synergistically to achieve desirable outcomes (8). Eventually, it boils down to the fact that an SA initiative can be considered successful if it "....promotes citizen voice to contribute to improved public sector performance" (9).

The essence of these deliberations at CPGA were clearly reflected in The COPASAH Charter and Call to Action for Social Accountability for Health which recognised that "SA provides marginalised communities access to governance processes in organic, accessible, and direct ways that enable community and citizen groups to engage with public authorities"(10). The Charter also recognised that accountability is a core obligation of people in authority within responsive public systems, who must take responsibility for their actions and check the abuse of power by political actors, service providers, and functionaries, to which the marginalised are more susceptible.

The CPGA discussions ended with a deepened understanding of the principles of SA to which COPASAH subscribes. These included a recognition that $S A$ in health 
initiatives must:

- enable marginalised communities to assert their rights and to participate in concrete actions to improve delivery of health services and to make distribution of resources more equitable;

- give voice to peoples' perspectives;

- be an empowering process where actors related to the health system are encouraged to address power imbalances that affect people's health;

- finally, SA must be linked to an action or advocacy plan which aims to influence or change health policies and programmes.

Without these elements, SA interventions can easily be reduced to, and mistaken for, a governance quick fix meant to strengthen the supply side by activating the demand side of programmes.

\section{References}

1. Ringold D, Holla A, Koziol M, Srinivasan S. Citizens and Service Delivery: Assessing the Use of Social Accountability Approaches in Human Development Sectors. World Bank Group; 2011 Dec [cited 2020 Nov 12]. Available from: file:///C:/Users/syatirajula/Downloads/ 657450PUBOEPI1065724B09780821389805.pdf

2. Ackerman JM. Social Development Papers. Participation and Civic Engagement. 2005 May 2005[cited 2020 Nov 12]; No. 86, Available from:http://documents.worldbank.org/curated/en/ 250451468048914790/pdf/

330110HROandOSAc0paper0inOSDVOformat.pdf

3. World Bank. World Development Report 2004: Making Services Work for Poor People. Washington, DC. World Bank; 2003[cited 2020 Nov 12]. Available from:https://openknowledge.worldbank.org/ bitstream/handle/10986/5986/WDR\%202004\%20-\%20English.pdf? sequence $=1$ \&isAllowed $=y$

4. Joshi A, Houtzager PP. Widgets or watchdogs? Public Management Rev. 2012; 14(2):145-62. Doi: 10.1080/14719037.2012.657837

5. Joshi A. Legal empowerment and social accountability: Complementary strategies toward rights-based development in health? World Dev. 2017 Nov[cited 2020 Nov 12]; 99:160-72. Available from https://www.sciencedirect.com/science/article/pii/ S0305750X17302425

6. Open Society Foundations (OSF). Capacity Building for Monitoring for Accountability in Health: Issues and Perspectives. AMHI/OSF; 2013 Available from: https://www.copasah.net/uploads/ 1/2/6/4/12642634/amhi cb paper final april 26.pdf

7. Joshi A. Reading the local context: $\mathrm{A}$ causal chain approach to social accountability. IDS Bulletin. 2014 Aug 28[cited 2020 Nov 12]. Available from: https://doi.org/10.1111/1759-5436.12101

8. Das A. How do we know we are making a dierence? Challenges before the practitioner of community monitoring processes in assessing progress and evaluating impacts. CHSJ, India, and COPASAH; 2013[cited 2020 Nov 12]. Available from:https:// www.copasah.net/uploads/1/2/6/4/12642634/

how_do_we_know_we_are_making_a_difference.pdf

9. Fox JA. Social accountability: What does the evidence really say? World Dev. 2015 Aug; 72: 346-61. Available from: https:// www.sciencedirect.com/science/article/pii/S0305750X15000704

10. COPASAH Charter and Call to Action for Social Accountability for Health, 2019. Available from: https://www.copasah.net/uploads/ 1/2/6/4/12642634/copasah_sa_charter_and_call_to_action.pdf

\section{Advancing the agenda for people-centred accountability of the private healthcare sector}

\section{KANCHAN PAWAR, ABHAY SHUKLA}

\section{Abstract}

The thematic track on accountability of the private and corporate healthcare sectors during the Community of Practitioners for Accountability and Social Action in Health (COPASAH) Global Symposium aimed to analyse the

Authors: Kanchan Pawar (corresponding author kanchan@sathicehat.org), Senior Consultant in Public Health, SATHI, Aman E Terrace, Dahanukar Colony, Kothrud, Pune, Maharashtra 411029 INDIA; Abhay Shukla (abhayshukla1@gmail.com), Senior Programme Coordinator, SATHI, Aman E Terrace, Dahanukar Colony, Kothrud, Pune, Maharashtra 411029 INDIA, and Member, Global Steering Committee, COPASAH.

To cite: Pawar K, Shukla A. Advancing the agenda for people-centred accountability of the private healthcare sector. Indian J Med Ethics. 2021 Oct-Dec; 6(4) NS: 281-85. DOI:10.20529/IJME.2021.075

Manuscript Editor: Sunita VS Bandewar

Peer Reviewers: Bijoya Roy

(C) Indian Journal of Medical Ethics 2021 emergence of the global trend of commercialisation of health systems, and the transition of healthcare from being a public good to a marketable commodity, at the cost of publicly funded healthcare in developing countries. It examined the implications of the lack of state regulation and oversight which has enabled the profit driven private healthcare sector to exploit vulnerable people through overcharging, malpractices and violations of patient's rights. Finally, the session addressed challenges in advocacy of patients' rights and showcased effective campaign strategies used by health activists in different countries to promote accountability of the private healthcare sector. Putting together learnings and insights from this track will help in contributing towards a powerful global counter-narrative, while providing activists with the tools to create awareness and engage with this critical issue.

Keywords: Accountability, private health sector, commercialising healthcare, advocacy, patients' rights 